\title{
An Employment Guarantee for the Urban Worker
}

\author{
J. Krishnamurty ${ }^{1}$ \\ Published online: 8 September 2020 \\ (c) Indian Society of Labour Economics 2020
}

\begin{abstract}
Public attention has focused on the problems of urban migrants returning to rural India due to the Covid-19 crisis. It may be months before the majority of returning migrants, including several different kinds of migrants, go back to urban areas and are absorbed in employment. We know that there is considerable movement of labour between rural and urban areas, some of it long-term and some of it short-term or periodic or circular. This is necessary and is not going to change. There is a case for extending the existing rural employment guarantee to urban India. This works through self-selection and can reach groups not always reached by other, equally important, welfare schemes. Given how little we know about the magnitudes and characteristics of migrant workers, it is desirable to proceed with caution. A pilot project may be started in one or more selected cities, without calling it a guarantee. Based on what we learn from this experience, it can then be extended to the whole of urban India. Components on adult education and training/retraining should be included in the project to improve skills, productivity and worker rights.
\end{abstract}

Keywords Urban Employment Guarantee · India · Lockdown · Migrant Workers

Public attention has rightly been on the immediate problems of migrants from urban areas returning to rural India as a result of the dramatic fall in urban employment due to the COVID-19 crisis. They have not always been welcomed to their villages; they are seen as an additional burden, especially since they are not remitting income to their families any more. Some have already returned to their erstwhile urban jobs at the call of their employers, but many appear unwilling to go back to urban areas after the pandemic. However, such initial reactions may not be a good guide to their intentions. Economic pressures may weigh against the memories of hardship before and during their journey. The insecure and poor quality of employment that awaits many of them may, therefore, not prove to be such a deterrent.

\footnotetext{
J. Krishnamurty

krishnamurty@gmail.com

1 Institute for Human Development, New Delhi, India
} 


\section{Who are the Migrants?}

When the migrants left urban India following the abrupt lockdown, little was known about them. And this continues to be the case. There are conflicting reports on their numbers and characteristics. How many men and women migrated back from the urban areas? What are their demographic particulars, education and skills, income, savings and consumption levels? They have rightly been called the invisible people or the nowhere people.

Estimates of the number of urban vulnerable workers, including migrants who might have lost their jobs and attempted to return to rural areas, are hard to come by. On the basis of Ravi Srivastava's pioneering work, the number of vulnerable workers in urban India can be placed at 169 million in 2017-2018. Of these, migrants of different kinds accounted for 111 million. ${ }^{1}$

We know that these are typically poor, unskilled persons who had insecure and poor-quality employment. Some were employees, regular or casual; others were probably self-employed in the informal sector. Also, some may have severed their rural links, if any; many others were not permanently residing in either urban or the rural areas. Many were involved in circular migration of varying durations, keeping a leg in both rural and urban areas, often driven by the lack of jobs in rural India to seek whatever was available in urban India.

Unlike in the case of the lockdown, there is no reason now why we should be unprepared for the eventual return of many reverse migrants back to urban India. The present time should be used productively to build up profiles of migrants who went back to the rural areas. Similar profiles should be built of other vulnerable workers in urban areas who were hit by the lockdown, but decided to stay. While some start has been made in this direction, much more needs to be done.

There is a view that ways should be found to productively absorb returnees into the rural labour market. It is true that some can and will find work in the villages or be trained to take up rural or urban occupations in their home State, wherever there are shortages of workers. However, we must recognize that in the short to medium run, there are severe limits to the capacity of the States to which they have returned to absorb these workers.

\section{Returning to Urban India}

Let us focus on migrants returning to urban India. Long-term migrants, especially those with skills in demand, would generally be absorbed easily, mostly with their prior employers. This may not always be the case, as their employers may have found others, possibly locals, to do the job. Again, some jobs will disappear as

\footnotetext{
1 See Ravi Srivastava, "Understanding Circular Migration in India: Its Nature and Dimensions, the Crisis under the Lockdown and the Response of the State," IHD Centre for Employment Studies, Working Paper 04/2020, Table 2. Further clarifications were obtained from the author by correspondence.
} 
employers are forced to close, or take the opportunity to downsize or to change their product line.

Migrants returning to self-employment would also face problems. Some may find it easier to restart, provided they have capital, and the product or service is in demand. Others, especially those in informal work or small-scale self-employment, may find it difficult to start again as social and economic networks on which they had depended may no longer exist. They would require capital, places to reside and locate their businesses, and they would have to attract back their clients and customers who may have found other sources of supply. Also, identifying and reaching new clients and customers may not be easy and could take time. The poorest would need to support themselves until work can be found.

What will happen to circular migrants? Much would depend on the degree and speed of economic revival in post-pandemic urban India. If revival is strong, many unskilled circular migrants may be absorbed in different sectors, albeit under conditions of precarious employment, as they would probably be in abundance and easily replaceable by others. On the other hand, revival may prove to be weak and either migrants will not be able to return or, more likely, they will return to poorly paid intermittent urban employment.

The process of reintegration is not likely to be smooth. It may be some months before the majority of returning migrants are absorbed into productive employment in the urban areas. Many may not be able to get back their prior employment and may end up unemployed or intermittently employed; they may be poorly paid and work on a casual basis.

\section{Towards a National Labour Market}

Given that there is rural distress in some parts of India and rapid growth of industry and services in others, we need to think in terms of fostering a national labour market. As the process of demographic transition is uneven across the States, labour force expansion is slowing or halting in some States, while in others labour force continues to grow quite rapidly. The post-lockdown reverse inter-State migration has made some political leaders and State administrations think of ways to keep this labour from migrating back after the pandemic is over. While efforts to create jobs for them at their current locations are commendable, it must be accepted that interState migration is needed to balance surpluses and shortages in the national labour market and this need will grow over the medium term.

While it is true that migrants from other States have not always been welcomed in the past, there is an increasing realization in the receiving States that they need these workers and that they must be treated better. One must hope that lessons have been learnt from the impact of the sudden withdrawal of migrants and that providing benefits for migrants will figure in the policies of self-interest of the receiving States. 


\section{Extending the Guarantee}

With our current realization that there is considerable movement of labour between rural and urban areas, some of it long term and some of it short term or periodic or circular, there is a case for extending the existing rural employment guarantee to urban areas all over India. No doubt, social security schemes, housing and other measures are needed, but so too is the employment guarantee.

The latter works through self-selection and can reach groups not always reached by other welfare schemes.

Recently, there has been some interest in the idea of an urban employment guarantee and this is attempted in Kerala under the Ayyankali Urban Employment Scheme (AUEGS). ${ }^{2}$ It aims to provide up to 100 days of wage employment per family in work such as waste management, water conservation and afforestation.

Another proposal was developed by Amit Basole and others from Azim Premji University in 2019. ${ }^{3}$ While they proposed including training and apprenticeship components, they did not have an adult literacy/education component. Many workers in the urban India, particularly above the age of 30, are illiterate or poorly educated and even those with education and some skills need training or retraining to compete in the changing labour market. Literacy and education also improve the knowledge of worker rights, the ability to organize and access to labour market information. Basole et al. (2019) also restrict coverage to urban areas other than the million-plus cities. The events following the lockdown in 2020 suggest that all urban areas need to be covered.

As in the case of its rural counterpart, MGNREGA, an urban programme will help to raise wages, improve bargaining power and improve infrastructure. In addition, it will expand literacy and education and create and enhance skills. This will also help in this way to raise the earnings and prospects of urban workers by improving their access to knowledge of labour market conditions, as well as their productivity through enhanced skills. As the economy develops and new products and technologies replace the old, there will be a great need to increase the knowledge and skills of workers.

Employers and their organizations and NGOs in the field of education should be active participants in this effort as they have the knowledge and capacity to help. Membership-based organizations like trade unions and associations of workers or the self-employed should also be involved. It may be possible to experiment with education or training vouchers which beneficiaries can encash with approved education/training providers.

Before extending the guarantee to urban areas, several prior steps are required. The labour market situation is rather fluid at the moment. We do not know how many persons would register for such a programme. Obviously, this would depend on the size of the vulnerable population currently in urban areas or planning to

\footnotetext{
${ }^{2} \mathrm{http} / / /$ lsgkerala.gov.in/en/schemes/ayyankali_urban_employment_guarantee_scheme.

${ }^{3}$ https://cse.azimpremjiuniversity.edu.in/wp-content/uploads/2019/04/SWI2019_Urban_Job_Guarantee. pdf.
} 
return to urban areas and on the proportion that would be attracted to it. This again would depend partly on the terms offered by the programme as well as the availability of employment opportunities elsewhere in the urban economy. Components relating to literacy, training and retraining would need time to plan and we have no way of knowing their likely demand. The costs of a programme to cover all urban areas cannot be estimated at this point as there are too many unknowns. Without this information, budget allocations cannot be planned or made.

A pilot project may therefore be started in one or more selected cities, without calling it a guarantee. The rules for registration need to be formulated carefully with some required minimum period of past residence in the urban area to qualify for benefits. The pilot project should aim to cover 1 lakh families for 100 days of work per family with a wage cost of Rs. 500 per day and some provision for the costs of literacy, education and training components. An initial allocation of Rs. 1000 crores per city may be made. The pilot project should have a duration of 1 year, with an independent review after 6 months, leading to a wider national programme. In the light of the findings, the affordability of extending the guarantee to all urban areas may be considered along with decisions about coverage and benefits to be provided.

Finally, a great deal of preparatory work needs to be done on terms of setting up the legal framework, administrative rules and procedures, linking up with potential partners and designing the benefits to be offered. The mix of benefits, public works, education and training, may also be varied depending on need and availability of facilities. As in the case of the MGNREGA, transparency is essential. Provisions for registration of beneficiaries, similar payment mechanisms, oversight and review (including social audits) should be built into the design of the project.

Publisher's Note Springer Nature remains neutral with regard to jurisdictional claims in published maps and institutional affiliations. 